University of New Hampshire

University of New Hampshire Scholars' Repository

$10-2010$

\title{
Managerial Epidemiology Is the Best Evaluation Tool for Our New Health Care System
}

\author{
Rosemary M. Caron \\ University of New Hampshire - Main Campus, rosemary.caron@unh.edu
}

Follow this and additional works at: https://scholars.unh.edu/hmp_facpub

Part of the Medicine and Health Sciences Commons

\section{Recommended Citation}

Caron, Rosemary M., "Managerial Epidemiology Is the Best Evaluation Tool for Our New Health Care System" (2010). Academic Medicine. 18.

https://scholars.unh.edu/hmp_facpub/18

This Letter to the Editor is brought to you for free and open access by the Health Management and Policy at University of New Hampshire Scholars' Repository. It has been accepted for inclusion in Health Management and Policy Scholarship by an authorized administrator of University of New Hampshire Scholars' Repository. For more information, please contact Scholarly.Communication@unh.edu. 


\section{Managerial Epidemiology Is the Best Evaluation Tool for Our New Health Care System}

To the Editor: Given that the overarching goal of health care reform is to improve the health of our population, the focus of health services management (as well as clinical practice) should be on the health of the populations they serve and not solely the fiscal health of their institutions. ${ }^{1}$ For this reason, I maintain that the science of public health management, namely managerial epidemiology, is the evaluation tool of choice. It is that branch of epidemiology that utilizes the traditional quantitative and causal reasoning methods taught in medical schools. It also incorporates the business aspects of health care that monitor demand, delivery, clinical outcome measurement, resource allocation, strategic analysis, program planning, and managed care. With 30 million more people in our health care system, we need to refine further our ability to provide equitable care while containing costs and ultimately reducing the demand for health care. Managerial epidemiology is "the scientific basis for any health system reform" 2 and is the science that must pervade professional preparation in both clinical and management practice.

Our health care leaders and providers need to be change agents in aligning social and economic objectives so that the improvement of population health is the prime metric of success. Integrating public health and personal health care policy and services is the silent and significant challenge. Distinctively, managerial epidemiology can measure the effectiveness of our newly revised system. It can tell us whether our reformed health care system is any more effective in improving the human condition. It is the metric to assess the implications of health care reform.

Rosemary M. Caron, PhD, MPH

Associate professor, University of New Hampshire, Durham, New Hampshire, and chair-elect, Association for University Programs in Health Administration, Public Health Faculty Network; rosemary.caron@unh.edu.

\section{References}

1 Evans RG. Healthy populations or healthy institutions: The dilemma of health care management. J Health Admin Educ. 1995;13: 453-472.

2 Roper WL, Cates WC. Managerial epidemiology: The basic science for health reform. J Health Admin Educ. 1993;11:621627.

\section{Time to Clarify Guidelines for Researchers and IRBs in Medical Education Research}

To the Editor: I applaud the requirement announced by the editor of Academic Medicine that reports of studies submitted to the journal must include details of ethical approval for the research or, if the author does not have access to a formal approval process, information about the treatment of the study's human participants. ${ }^{1}$

In addition to the editor's five reasons for this requirement, I would add another one: that students or residents or even faculty recruited for educational research studies are potentially vulnerable to coercion to participate, loss of privacy, or adverse actions.

It is not always easy to balance this potential vulnerability of students, residents, and faculty against existing regulations and researchers' goals in recruiting subjects. Medical education research may be exempt from institutional review board (IRB) approval, under the provisions of Subpart A, Section 46.101 of the Federal Code of Regulations regarding "research conducted in established or commonly accepted educational settings, involving normal educational practices." 2 However, there appears to be considerable variation in the way this provision is interpreted and implemented by different IRBs, as previously reported in Academic Medicine. ${ }^{3-5}$

I hope the journal will publish more discussion about the ethics of medical education research. It's time to clarify the guidelines for researchers and IRBs.

Nicholas H. Fiebach, MD

Professor of clinical medicine and vice chair for graduate and continuing medical education, Department of Medicine, Columbia University College of Physicians and Surgeons, New York, New York; nhf2101@columbia.edu.

\section{References}

1 Kanter S. Ethical approval for studies involving human participants: Academic Medicine's new policy. Acad Med. 2009;84:149-150.

2 U.S. Department of Health and Human Services. Code of Federal Regulations. Title 45: Public Welfare. Part 46: Protection of human subjects. Subpart A, Section 46.111: Criteria for IRB approval of research. Available at: http://www.hhs.gov/ohrp/humansubjects/ guidance $/ 45 \mathrm{cfr} 46 . \mathrm{htm}$. Accessed May 31, 2010.

3 Dyrbye LN, Thomas MR, Mechaber AJ, et al. Medical education research and IRB review: An analysis and comparison of the IRB review process at six institutions. Acad Med. 2007;82: 654-660.

4 Carline JD, O'Sullivan PS, Gruppen LD, Richardson-Nassif K. Crafting successful relationships with the IRB. Acad Med. 2007; 82(10 suppl):S57-S60.

5 Dyrbye LN, Thomas MR, Papp KK, Durning SJ. Clinician educators' experiences with institutional review boards: Results of a national survey. Acad Med. 2008;83:590-295.

\section{A Framework for Designing Training in Medical Advocacy}

To the Editor: In their January article, Earnest et al ${ }^{1}$ adeptly highlight the need for the creation and delivery of more formalized training in medical advocacy. Toward this worthwhile goal, we offer the following framework of learning objectives, derived from our experiences teaching advocacy to medical students at the Boston University School of Medicine (BUSM). Our program is student-led in conjunction with mentorship from faculty at BUSM and the professional advocates at the National Center for Medical-Legal Partnership. ${ }^{2}$ Over the past six years, it has evolved from a single elective to a multiyear curriculum with both clinical and preclinical components. The learning objectives we present here arose from this continuing curricular development and might provide a starting point for other institutions interested in designing formalized training in medical advocacy for medical students.

To skillfully engage in the types of advocacy that Earnest et al describe, medical students need to develop skills in advocacy theory, execution, and communication. Formal study of the theory of advocacy helps medical students define their roles as advocates and explore their positions along the spectrum of physician advocacy. 
Experience in executing defined advocacy projects removes potentially formidable barriers to using advocacy in clinical settings by honing skills and developing both competence and confidence. Finally, training in communication enables medical students to translate clinical observations for wider audiences and to teach advocacy to other medical professionals.

Learning objectives dealing with advocacy theory might include (1) formally identifying and distinguishing between the roles that physicians must, should, and could perform within the spectrum of physician advocacy, and (2) developing a rigorous understanding of the social determinants of health.

Learning objectives centered on advocacy execution might include practice in distilling clinical observations from multiple patients into a well-defined issue in need of advocacy, then engaging in a smallscale advocacy project. Examples include writing an op-ed for a local paper or developing an "advocacy code card" that clerks can use to help their patients receive benefits like Womens, Infants, and Children nutrition vouchers.

Learning objectives dealing with advocacy communication might include completing a press release, oral presentation, or lecture for a nonmedical community, or presenting a patient whose clinical course is complicated by socioeconomic issues to a group of medical peers.

Daniel A. Dworkis

MD-PhD candidate, Department of Molecular Medicine, Boston University School of Medicine, Boston, Massachusetts; ddworkis@bu.edu.

MaryAnn B. Wilbur

MD-MPH candidate, Boston University School of Medicine, Boston, Massachusetts.
Megan T. Sandel, MD, MPH

National medical director, National Center for Medical-Legal Partnership, Boston, Massachusetts.

\section{References}

1 Earnest MA, Wong SL, Federico SG. Perspective: Physician advocacy: What is it and how do we do it? Acad Med. 2010;85:63-67.

2 National Center for Medical-Legal Partnership Web site. Available at: http://www.medicallegalpartnership.org/national-center. Accessed June 6, 2010.

In Reply: We applaud the efforts described by Dworkis et al at BUSM in developing a longitudinal educational experience in advocacy. They describe a useful framework in which to plan and implement a curriculum where advocacy competencies are developed as a part of physician practice and professionalism. Their program and our LEADS (Leadership Education Advocacy Development Scholarship) program at the University of Colorado, as well as a handful of other programs across the country, represent a growing interest in this type of training. The success of these emerging courses demonstrates the feasibility of implementing such curricula.

In our article, we highlight several examples of physicians incorporating advocacy into their professional roles. Each example emphasizes an advocacy-related competency or skill. We assert that these competencies need to be incorporated into medical training so that every physician achieves some basic level of competence in advocacy. Reaching this goal would require that advocacy become an accepted component of professionalism and that licensing and accrediting bodies recognize it as such. Only through these means will we move beyond our current status of professional aspiration without commensurate professional action. We see these curricular innovations as a critical step in the process toward institutionalizing these values and developing the skills. Given the variation among current programs, an important next step is to promote collaboration and ultimately consensus on a common set of competencies and learning objectives. Achieving this goal will require new funding sources and the creation of new courses at additional medical schools; these courses should be rigorously evaluated and validated through peer review.

To our knowledge, the most organized effort to move this agenda has been through the Center for Medicine as a Profession, which sponsors a grants program supporting such curricular development. A key component of their initiative has been to create dialogue among interested programs and physicians. Perhaps this group could serve as a nidus for a larger conversation.

As we move forward toward the goals stated above, we must keep in mind their purpose. The practice of advocacy should produce measurable outcomes for patients and populations we serve and help create a health system that is more responsive to the health needs of individuals and communities.

Mark A. Earnest, MD, PhD

Associate professor, Department of Medicine, codirector, LEADS Program, and director of interprofessional education, University of Colorado Denver School of Medicine, Aurora, Colorado; mark.earnest@ucdenver.edu.

Shale L. Wong, MD, MSPH

Associate professor of pediatrics, codirector, LEADS program, and health policy fellow, Robert Wood Johnson Foundation, University of Colorado Denver School of Medicine, Aurora, Colorado.

Steven G. Federico, MD

Assistant professor of pediatrics and director of school-based health centers, Denver Health, University of Colorado Denver School of Medicine, Aurora, Colorado. 